U.S. DEPARTMENT OF THE INTERIOR

U.S. GEOLOGICAL SURVEY

\title{
BEDROCK GEOLOGIC MAP OF THE IPSWICH QUADRANGLE, ESSEX COUNTY, MASSACHUSETTS
}

By William H. Dennen

Prepared in cooperation with the COMMONWEALTH OF MASSACHUSETTS

DEPARTMENT OF PUBLIC WORKS 


\section{GEOLOGIC MAP SYMBOLS}

\section{COMMONLY USED ON MAPS OF THE UNITED STATES GEOLOGICAL SURVEY}

(Special symbols are shown in explanation)

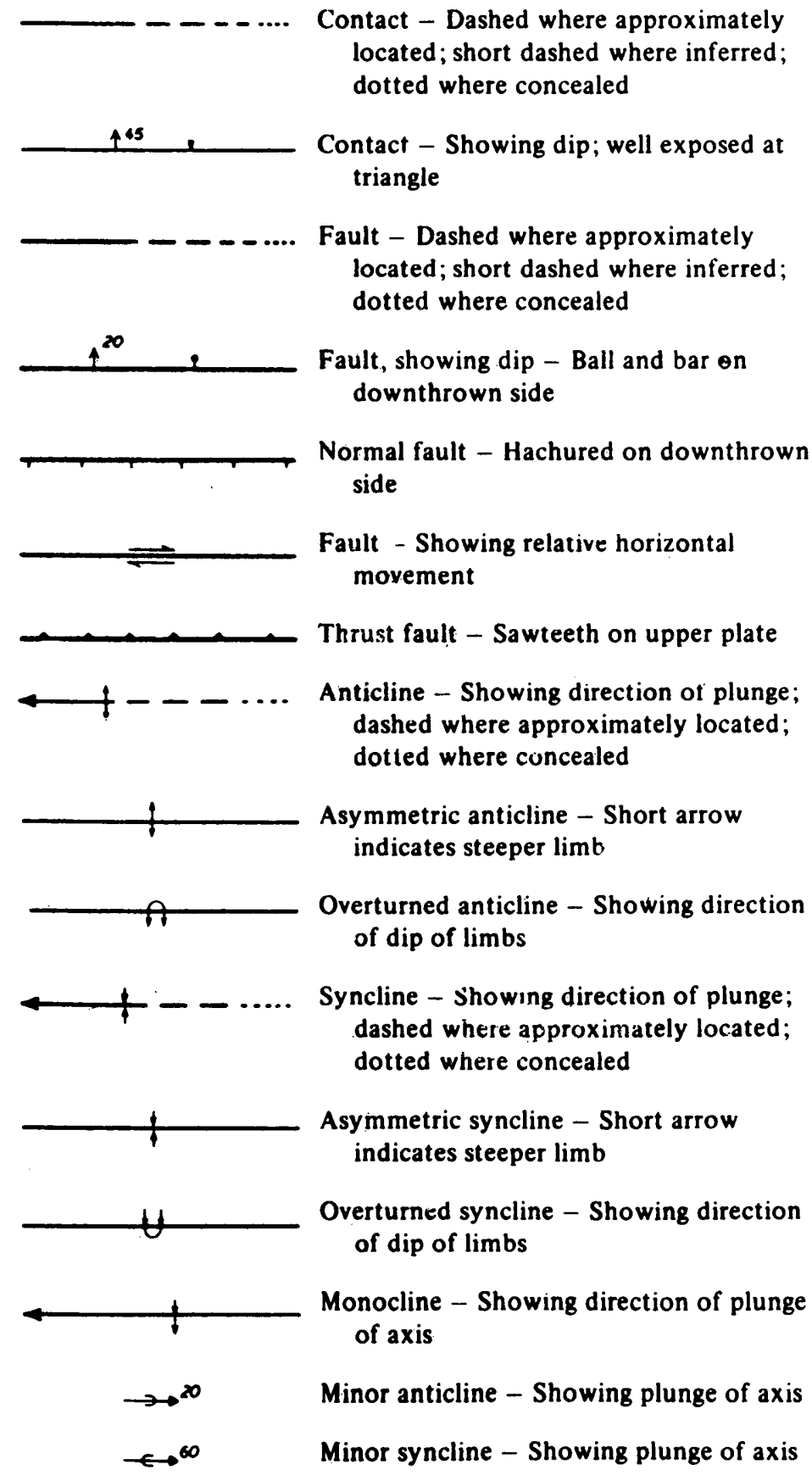

Strike and dip of beds - Ball indicates top of beds known from sedimentary structures

$\stackrel{x}{2}$ Inclined $\oplus$ Horizontal

+ Vertical +40 Overturned

Strike and dip of foliation

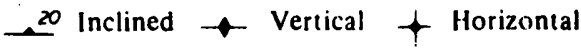

Strike and dip of cleavage

15 Inclined Vertical f Horizontal

Bearing and plunge of lineation

$15 \leftarrow$ Inclined $\bullet$ Vertical $\longleftrightarrow$ Horizontal

Strike and dip of joints

$\ldots . .40$ Inclined $\rightarrow$ Vertical $\rightarrow$ Horizontal

Note: planar symbols (strike and dip of beds, foliation or schistosity, and cleavage) may be combined with linear symbols to record data observed at same locality by superimposed symbols at point of observation. Coexisting planar symbols are shown intersecting at point of observation.

Shafts

๑ Vertical Inclined

Adit, tunnel, or slope

$\succ$ Accessible * Inaccessible

$\times$ Prospect

Quarry

x Active Abandoned

Gravel pit

$\times$ Active $\times$ Abandoned

Oil well

- Drilling $\phi$ Shut-in $\phi$ Dry hole

* Gas Show of gas abandoned

- Oil Show of oil 